Volume 37, n. 2 - p. 499 - 520, abr./jun. 2019 - Florianópolis

Monique Priscila de Abreu Reis Instituto Federal de Educação, Ciência e Tecnologia de São Paulo - IFSP

Email: moniquepriscila@yahoo.com.br

(D) https://orcid.org/0000-0002-8926-8286

Tatiane Cosentino Rodrigues Universidade Federal de São Carlos UFSCar

Email: tatiane.cosentino@gmail.com (D) https://orcid.org/0000-0002-4402-2805

Recebido em: 27/09/2017

Aprovado em: 09/03/2019

\section{Relações étnico-raciais na formação de professores/as de teatro}

\section{Monique Priscila de Abreu Reis Tatiane Cosentino Rodrigues}

\section{Resumo}

Tendo como referência a Lei 10.639/2003, buscou-se compreender como os(as) futuros(as) professores(as) de teatro estão sendo formados(as) para educação para as relações étnico-raciais. Considerando a área de arte como prioritária na implementação da temática étnico-racial na Educação Básica - conforme disposto nas Diretrizes Curriculares para o Ensino de História e Cultura Afrobrasileira e Africana e para Educação das Relações Étnico-raciais e identificando uma lacuna teórica no que diz respeito especificamente à formação de professores(as) de teatro na temática em questão, buscou-se a elaboração, baseando-se em entrevistas com pesquisadores(as) da área, de possíveis propostas de conteúdos, abordagens e metodologias de formação inicial para professores(as) de teatro na perspectiva da educação para as relações étnico-raciais e do ensino de história e cultura afrobrasileira e africana. Como resultado, trazemos para o debate possibilidades formativas centradas em uma aproximação entre universidade e comunidade contemplando atividades de pesquisa e extensão, novas epistemologias e diferentes formas de conceber e realizar o fazer teatral.

Palavras-chave: Formação de professores(as). Teatro. Relações étnico-raciais. 


\section{Abstract}

Keywords:

Training

teachers.

Theater. Ethnic-

racial

relationships.

\section{Ethnic-racial relationships in theater teacher training}

With reference to Law 10.639/2003, it was aimed to understand how future theatrical teachers are being trained to education for ethnic-racial relations. Considering the area of art as a priority in the implementation of ethnicracial themes in Basic Education - as set out in the Curriculum Guidelines for Teaching Afro-Brazilian and African History and Culture and for Education of Ethnic-Racial Relations - and identifying a theoretical gap in which specifically concerns the training of theater teachers in the theme in question, it was sought the elaboration, based on interviews with researchers in the area, of possible content proposals, approaches and methodologies of initial training for teachers / the theater in the perspective of education for ethnic-racial relations and the teaching of Afro-Brazilian and African History and Culture. As a result, we bring to the debate formative possibilities centered on an approximation between university and community contemplating activities of research and extension, new epistemologies and different ways of conceiving and performing theatrical performance.

\section{Resumen}

\section{Relaciones étnico-raciales en la formación de profesores de teatro}

Con referencia a la Ley 10.639/2003, se buscó comprender cómo los/as futuros/as profesores/as de teatro están siendo formados/as para educación para las relaciones étnico-raciales. Considerando el área de arte como prioritaria en la implementación de la temática étnico-racial en la Educación Básica - conforme a lo dispuesto en las Directrices Curriculares para la Enseñanza de Historia y Cultura Afro-brasileña y Africana y para la Educación de las Relaciones Étnico-raciales - e identificando una laguna teórica en el que se refiere específicamente a la formación de profesores/as de teatro en la temática en cuestión, se buscó la elaboración, basándose en entrevistas con investigadores/as del área, de posibles propuestas de contenidos, enfoques y metodologías de formación inicial para

Palabras clave: Formación de professores.

Teatro.

Relaciones étnico-raciales. profesores/las de teatro en la perspectiva de la educación para las relaciones étnico-raciales y de la enseñanza de Historia y Cultura Afro-brasileña y Africana. Como resultado, traemos para el debate posibilidades formativas centradas en una aproximación entre universidad y comunidad contemplando actividades de investigación y extensión, nuevas epistemologías y diferentes formas de concebir y realizar el hacer teatral. 


\section{Introdução}

O presente artigo é resultado de pesquisa de mestrado que buscou compreender de quais maneiras as universidades estão incorporando nos currículos das Licenciaturas em Teatro a educação para as relações étnico-raciais, em consonância com o campo normativo ${ }^{1}$ que evidencia a arte como área prioritária para a implementação da temática em questão na Educação Básica.

A dissertação de mestrado foi organizada em duas linhas de análise: a primeira parte voltada à pesquisa bibliográfica, com a realização de levantamento em bases de dados reconhecidas pelas pesquisas e discussões nos campos da educação e/ou das artes, e à pesquisa documental, com análise do Projeto Político Pedagógico (PPP) e das ementas das disciplinas dos cursos de Licenciatura em Teatro da Universidade Federal de Minas Gerais (UFMG) e de Licenciatura em Artes/Teatro da Universidade Estadual Paulista (Unesp). A segunda parte apresenta as análises de entrevistas semiestruturadas com pesquisadores(as) ligados à área de Teatro e também com estudantes concluintes dos cursos de Licenciatura das universidades pesquisadas.

Este artigo corresponde ao segundo momento do trabalho, ${ }^{2}$ em que se buscou privilegiar uma perspectiva propositiva, pensando na elaboração, por meio de entrevistas com pesquisadores(as) da área, de possíveis propostas de conteúdos, abordagens e metodologias de formação inicial para professores(as) de teatro na perspectiva da educação das relações étnico-raciais e do ensino de história e cultura afro-brasileira e africana.

Foram realizadas entrevistas semiestruturadas com três pesquisadores $(\text { as })^{3}$ atuantes em cursos de graduação em Teatro. O roteiro das entrevistas contou com dez questões, que foram ampliadas ao longo da conversa. As questões versavam sobre a experiência dos(as) participantes como formadores(as) de professores(as) de teatro e suas experiências com a temática racial, culminando com proposições de reestruturação do currículo e a possibilidade de uma pedagogia teatral que aborde particularmente a perspectiva da educação para as relações étnico-raciais.

Da UFMG, entrevistamos o professor Ricardo Carvalho de Figueiredo, que possui artigos publicados nos anais da Associação Brasileira de Pesquisa e Pós-graduação em Artes Cênicas (Abrace) e em periódicos sobre formação de professores(as) de teatro. O professor tem sido um grande apoiador, nas disciplinas que ministra e nos projetos que coordena, dos(as) estudantes, principalmente negros(as), que querem realizar atividades relacionadas à temática racial. 
Da Unesp foi entrevistada a professora Carminda Mendes André, que tem importantes publicações sobre ensino de teatro e realiza atividades de pesquisa junto às manifestações da cultura afro-brasileira, como a Congada.

O terceiro entrevistado foi o professor Zeca Ligiéro, da Universidade Federal do Estado do Rio de Janeiro (Unirio), autor de reconhecida pesquisa sobre as culturas afrobrasileira e africana na interface com o teatro. O professor tem importantes obras, que focalizam a complexidade das performances culturais afro-brasileiras e ameríndias, propondo o Outro Teatro.

A metodologia de pesquisa utilizada foi inspirada nos princípios da teoria fundamentada, conforme Strauss e Corbin (2008). A teoria fundamentada, de natureza exploratória, indica que a construção da teoria é realizada a partir dos dados coletados e analisados, possibilitando a explicação do fenômeno investigado.

Assim, os enquadramentos teórico e analítico da pesquisa foram sendo construídos a partir dos dados coletados das entrevistas, dos quais se originaram quatro categorias: trajetória de vida enquanto constituição do saber docente; projetos de extensão e práticas pedagógicas; novas epistemologias; Outro Teatro. Cada categoria representa possibilidades para (re)pensar a formação inicial de professores(as) de teatro.

De forma propositiva, este trabalho revela um amplo campo de possibilidades para reestruturação do currículo das Licenciaturas em Teatro considerando a questão étnico-racial e a formação para o ensino de história e cultura afro-brasileira e africana.

\section{Trajetória de vida enquanto constituição do saber docente}

As trajetórias de vida e os percursos de construção das experiências no âmbito da educação foram fundamentais para a formação docente dos(as) entrevistados(as). Da mesma forma, é em meio aos encontros de vida que estas trajetórias acabam por se deparar com a questão étnico-racial, emergindo daí uma busca pela construção de conhecimentos sobre a temática. Nos três casos analisados, o contato com a questão racial não partiu de um currículo ou de uma política institucional de formação inicial. Surgiu da necessidade de se trabalhar a temática a partir de situações de contato com a população negra e também do encontro com profissionais que pesquisavam a temática.

O professor Ricardo Figueiredo formou-se em Licenciatura em Artes Cênicas na Universidade Federal de Ouro Preto (Ufop) e logo que se graduou teve a possibilidade de trabalhar como professor substituto nesta instituição. Para ele, a participação em projetos de extensão foi fundamental para a sua formação durante a graduação e também enquanto 
professor, como forma de "sair da universidade, sair da sala de aula, do espaço físico e ir para a cidade" (FIGUEIREDO, 2016, informação oral ${ }^{4}$ ), buscando a construção de relações educativas com os cidadãos. Depois, o professor atuou como docente na Educação Básica, até que ingressou como professor efetivo na UFMG, no curso de Licenciatura em Teatro. $\mathrm{O}$ contato com a temática étnico-racial veio da prática, a partir da demanda de situações específicas. Como exemplo, o professor cita os(as) bolsistas do Programa Institucional de Bolsa de Iniciação à Docência (Pibid), que, ao chegarem à escola pública de Educação Básica, constataram que a maior parte dos(as) alunos(as) eram negros(as), percebendo, em seguida, como a cultura e as identidades destes jovens eram desconsideradas e descartadas e, por isso, resolveram realizar projetos a partir dos princípios da Lei 10.639, de 9 de janeiro de 2003. O docente entrevistado, então, em conjunto com os(as) bolsistas, passou a pensar em como trabalhar história e cultura afro-brasileira por meio do teatro. As situações vivenciadas nos projetos e nas disciplinas trouxeram a temática para a discussão, e o professor Figueiredo mostrou-se aberto à construção de subsídios teóricos para auxiliar os estudantes da Licenciatura. No entanto, o professor afirmou que a temática não aparece, de início, nos planos de ensino das disciplinas que ministra, como foco.

A professora Carminda André formou-se em Bacharelado em Teatro pela Escola de Comunicação e Artes da Universidade de São Paulo (USP) e começou a dar aula de formação de atores antes de concluir o curso, no quarto ano. Ela ressalta que, mesmo exercendo durante muito tempo as funções de diretora e atriz, o lugar de professora sempre esteve presente, pois não parou de lecionar desde que começou. Para a professora, toda a sua formação na graduação foi eurocêntrica, e o contato com a temática racial se deu a partir do ingresso como docente na Unesp e do encontro com o professor Alberto Ikeda. Este professor ministrava a disciplina Folclore, que depois passou a ser chamada de Cultura Popular, e levava os(as) alunos(as) para festas populares, como a Congada, as Festas de Reis, as Festas de São Benedito, entre outras. Carminda André relata que foi acompanhando o professor Ikeda e os(as) alunos(as) em uma Festa de São Benedito, em Aparecida, que ela despertou para a arte afro-brasileira. Para ela, foi uma experiência muito forte, e, a partir disso, aos poucos, passou a pesquisar expressões culturais, festas religiosas, não só de influência afro-brasileira mas também ameríndia.

O professor Zeca Ligiéro iniciou suas atividades docentes muito jovem, dando aula para o antigo ginásio, trabalhando com Hilton Carlos de Araújo, considerado como um dos pioneiros do teatro na educação. No mesmo período em que foi aprovado o ingresso da arte no currículo escolar da educação pública, como um programa do governo federal, o professor passou a trabalhar com formação de professores(as) no antigo Serviço Nacional de Teatro 
(SNT). Nesse período, na década de 1970, o professor relata que não tinha relação com as tradições africanas. Ele conta que, na zona sul do Rio de Janeiro, onde trabalhava, havia poucos(as) alunos(as) e professores(as) negros(as), e o tema não era abordado. O professor graduou-se em Direção Teatral pela Unirio em 1972.

O contato com a cultura afro se deu quando Zeca Ligiéro foi trabalhar com grupos de teatro amadores em São Gonçalo. Lá o professor percebeu que em torno de $80 \%$ dos(as) participantes eram negros(as) e, como sempre, teve interesse em criar espetáculos a partir dos atores/atrizes, que eram negros(as), então as questões da cultura afro emergiram, bem como as questões dos preconceitos, das opressões. Nesse contexto, foi montado o espetáculo Realidades e Lendas de São Gonçalo, que depois virou livro. ${ }^{5}$ Foi assim que começaram suas pesquisas sobre cultura afro-brasileira, que já resultaram em importantes publicações, as quais constituem referências para o trabalho com a temática afro-brasileira.

Partindo da constatação de que, para os(as) professores(as) entrevistados(as), o contato com a temática não se originou da formação acadêmica inicial, mas das vivências e encontros, poderíamos questionar quantos professores universitários vão passar pela vida acadêmica e trabalhar com estudantes sem ter este despertar para a temática étnico-racial? E quantos estudantes dos diferentes pertencimentos raciais passarão pela formação de professores(as) sem ter contato com a temática?

Dessa forma, é possível compreender que a trajetória de vida na intersecção com a trajetória docente pode trazer ou não o despertar para a cultura afro-brasileira. Nas entrevistas com os docentes, deparamo-nos com três situações distintas: na primeira, a temática é mobilizada diante de situações específicas, por influência direta dos pertencimentos étnicoraciais dos(as) participantes de projetos ou dos(as) alunos(as); em outra, o contato com as manifestações afro-brasileiras tem gerado uma mudança de perspectiva e vem sendo objeto de pesquisas recentes; e, por fim, há uma terceira via, que se caracteriza pelo envolvimento orgânico com a temática afro-brasileira, incorporada como tema de pesquisa, no planejamento das disciplinas e na produção bibliográfica.

\section{Projetos de extensão e práticas pedagógicas}

O professor Ricardo Figueiredo relata que sua formação foi permeada por atuações em projetos de extensão. No seu entendimento, é fundamental, na formação de professores(as) de teatro, a formação educativa em convívio com a comunidade. Para ele, os(as) estudantes devem ser levados(as) a refletir sobre como podem contribuir com o lugar em que estão e reconhecer que "o teatro que não é meu, que é muito mais do outro" (FIGUEIREDO, 2016). 
O docente afirma que uma relação intensa entre a extensão e a formação de professores(as) é necessária. Para ele, a extensão é o lugar das possibilidades.

Para o professor, o Pibid é muito relevante, pois parte de uma formação conjunta: o(a) professor(a) da Educação Básica, em parceria com o(a) professor(a) do Ensino Superior, formando futuros licenciandos em teatro. E essa formação conjunta coloca o(a) estudante em contato direto com a realidade da escola. Ele coordena um grupo de estudantes do Pibid que trabalham com teatro no Ensino Fundamental II.

A partir desta imersão no ambiente escolar por meio do Pibid, os(as) estudantes relatam diferentes situações e buscam em conjunto propostas de atuações específicas em teatro. Como exemplo, o professor cita o caso de estudantes negros(as) do Pibid, participantes de movimento de teatro negro na universidade, que, ao se depararem com o descaso para com a cultura afro-brasileira na escola, decidiram pensar em propostas:

E trabalhando no Pibid, eles constataram, desde sempre, que a escola pública tem majoritariamente uma população negra e como que isso é simplesmente ignorado pela escola. As práticas culturais e a identidade destes jovens são descartadas. Então, eles trabalharam no Pibid em 20142015 e, logo no início, tiveram uma vontade muito grande de levar a Lei 10.639/2003. Passamos a pensar o que o teatro poderia fazer. E uma das sugestões, num primeiro momento, foi trabalhar, por exemplo, com a história do Chico Rei, texto de Adélia Carvalho. [...] Então eles começaram lendo o texto. Começaram a investigar as relações, o que está para uma determinada cultura, o que foi. Isto pensando em Ouro Preto, esta transição, o Chico Rei capturado na África, trazido para Ouro Preto, em um momento histórico. Pensando nessas relações de criação com os alunos. O que significa este coletivo, a oralidade, pensando as relações étnico-raciais. (FIGUEIREDO, 2016).

Nesse relato, foi possível identificar como a imersão na escola proporcionou aos(às) estudantes o contato com uma realidade em que a cultura afro-brasileira é silenciada. Essa constatação, aliada ao fato de a maioria dos(as) alunos(as) da escola serem negros(as) e terem suas histórias negligenciadas, fez com que os(as) estudantes pensassem em projetos para inserir a cultura afro-brasileira. Vale ressaltar: os(as) estudantes da UFMG participantes deste projeto eram negros(as) e conheciam a Lei 10.639/2003, o que refletiu em um cuidado para com a escolha da abordagem, de criação conjunta com os(as) alunos(as) da escola, buscando um resgate histórico.

No Pibid, os(as) estudantes vão para a escola e ali entram em contato com alunos(as) e professores(as) da Educação Básica, fazem planejamentos, refletem sobre diferentes questões e vão se construindo enquanto futuros(as) professores(as). Por meio da atuação prática no Pibid, os estudantes entram em contato com outras questões que permeiam a relação ensino/aprendizagem, descobrindo, muitas vezes, que as técnicas apreendidas na graduação 
são interessantes para o trabalho do ator e da atriz, mas que muitas não encontram espaço na escola, na sala de aula, onde o teatro assume uma outra configuração como espaço de criação e transformação. Nesse sentido, os projetos de criação teatral na escola devem fazer sentido para os(as) alunos.

A disciplina Projetos Especiais em Educação, ministrada pelo professor Ricardo Figueiredo, apesar de não conter a temática afro-brasileira na ementa e no plano de ensino, oferece liberdade para os(as) estudantes escolherem o tema de seus projetos. O objetivo da disciplina é pensar em projetos de teatro fora da escola. A partir do interesse de estudantes, principalmente negros(as), têm sido desenvolvidos projetos que abordam as questões raciais e a cultura afro-brasileira.

O professor Ricardo Figueiredo considera importante que o currículo contemple uma disciplina específica sobre história e cultura afro-brasileira e educação para as relações étnicoraciais.

Hoje nós estamos nesse século XXI, que tanto a diversidade de olhares, de matrizes e das minorias estão colocadas para nós o tempo inteiro, para pensar a Educação Básica, para pensar a formação de professores. Então, não ter uma disciplina com este enfoque é tapar o sol com a peneira. É mesmo deixar excludente esta discussão, que está colocada para nós o tempo inteiro, e que a gente vive o tempo inteiro na nossa sociedade, de racismo, de exclusão, de mortalidade. (FIGUEIREDO, 2016).

A partir de suas experiências e vivências, o docente considera que deixar esta temática apenas como tema transversal, que deve permear todas as disciplinas, tem tido como resultado, no currículo praticado, a ausência de abordagens na área.

Figueiredo cita o professor Marcos Antônio Alexandre, do Departamento de Letras, que também ministra aulas na graduação de teatro, com as disciplinas Teorias do Texto Dramatúrgico e do Texto Espetacular, como importante referência no trabalho com a cultura afro-brasileira na UFMG. Marcos Alexandre é um dos coordenadores do projeto de extensão Contos de Mitologia. Nesse projeto, realizam-se oficinas para professores(as) da Educação Básica, não necessariamente professores(as) de Arte, e ainda contação de histórias com mitologias africanas e

[...] uma discussão muito na linguagem artística e teatral, porque os oficineiros geralmente são do teatro, para apresentar ao professor [da Educação Básica] o quanto que isto [o racismo] está enraizado em determinadas práticas da nossa sociedade e que as pessoas não percebem. (FIGUEIREDO, 2016). 
$\mathrm{Na}$ entrevista com o Figueiredo, ficou evidente que, mesmo que não sejam seus temas de pesquisa, a temática étnico-racial e a cultura afro-brasileira têm aparecido com frequência, a partir da demanda de estudantes negros(as), que estão cada vez em maior número na universidade, e do contato com situações de racismo e silenciamento que acontecem nos ambientes em que os projetos de extensão são desenvolvidos. O que demanda do professor a construção conjunta com seus(suas) orientandos(as) de formas de abordagem da temática nas diversas atividades.

Fica evidente o quanto que a vivência de práticas pedagógicas na Educação Básica proporciona aos(às) estudantes o contato com todos(as) os problemas que cercam o meio educacional em seu cotidiano e demandam pesquisa e planejamento de ações específicas no campo do teatro.

Projetos de extensão, como no caso do Pibid, constituem espaços relevantes para a formação de professores(as) de teatro no âmbito das possibilidades de práticas pedagógicas, a partir da realidade, da demanda do público-alvo e dos conflitos. Cabe salientar que nem todos(as) os(as) graduandos(as) participantes dos projetos terão a sensibilidade para perceber as violências raciais sem formação específica na área. Nos casos citados, os(as) estudantes perceberam as situações, pois já estavam atuando em coletivos negros, estudando a legislação da área e vivenciando estas violências, devido também ao pertencimento étnico-racial e às experiências dele decorrentes.

\section{Novas epistemologias}

A professora Carminda André (2016, informação oral ${ }^{6}$ ) expressou em entrevista concedida que é possível uma pedagogia do teatro centrada em novas epistemologias, trazendo para a universidade os modos de fazer, os saberes de mestres e mestras de origem afro-brasileira e ameríndia.

No entendimento da docente, há uma hierarquia de saberes, na qual o pensamento cientificista é hegemônico, branco e eurocêntrico. Ela reforça a tese de que é preciso trazer as epistemologias do Sul para se pensar novas configurações para o currículo. ${ }^{7}$

Carminda André defende que a compreensão do currículo a partir das epistemologias do Sul exigiria uma mudança na concepção das disciplinas curriculares. Para ela, o ideal seria que não se acrescentasse mais uma disciplina sobre "expressões culturais ou história da afrodescendência brasileira", mas que a temática estivesse imbricada com conteúdos de todas as disciplinas. 
[...] se queremos de fato ser contaminados pelas epistemologias do Sul que as expressões afrodescendentes podem nos trazer, temos que contaminar isso dentro do currículo escolar. [...] Isso é uma coisa que nós [Unesp] inclusive estamos trazendo. A história do teatro da América Latina, muito mais forte, cada vez mais forte que o teatro europeu. $O$ teatro do mundo, multicultural para vir para cá. Queremos que o currículo tenha esta força, esta descentralização europeia, para uma centralidade mais latinoamericana, pensando como um lugar de afrodescendência, de hibridismo, com negros, brancos, índios e todas as misturas que há. (ANDRÉ, 2016).

É possível perceber que o contato com mestres e mestras torna-se um importante elemento de aprendizado para se pensar o teatro de outras formas que não a do teatro ocidental, centrado no texto dramatúrgico. A professora nos relatou uma experiência de formação com o mestre africano Toumani Kouyaté. Neste curso, a professora vivenciou o aprendizado sobre a tradição milenar africana ligada à oralidade, a toda uma construção a partir do poder e da força da palavra. Vivenciou outros modos de construção da relação do corpo com o espaço. É uma nova concepção de conhecimento em teatro, que vem a partir do contato com mestres e mestras africanos(as), guardiões(ães) deste conhecimento.

Em outro momento da entrevista, a professora Carminda André enfatizou seu trabalho com intervenção urbana, realizado juntamente com estudantes, que também se constitui como espaço para formação. No trabalho de campo, como no caso das intervenções urbanas, professora e estudantes atuam diretamente em contato com as pessoas. Agem e sofrem a ação por meio da interação e da interlocução. E, nesta troca, é relatada a construção de conhecimentos atuando na região em que se situa a universidade, conhecendo a situação da comunidade e resgatando histórias a partir da oralidade, tendo a arte como mediadora deste processo. Nesse sentido, Carminda propõe pensar a arte como formação ética, pautada no respeito e na valorização das diferenças.

Trazemos para o debate a proposta de pensar o currículo dos cursos a partir de novas epistemologias. Incorporando saberes, experiências e modos de fazer ligados a tradições ancestrais, enraizados na constituição de diferentes formas de conhecimento. Levando os(as) estudantes a terem contato com diferentes tipos de manifestações artísticas e culturais no próprio local em que permanecem vivos(as) e têm suas formas, cores e crenças. Mas também trazendo os conhecimentos ancestrais para a universidade, por meio de ações com que mestres e mestras possam compartilhá-los com os(as) formandos(as) em Licenciatura em Teatro.

\section{Outro Teatro}

O professor Zeca Ligiéro trabalha com um conceito denominado por ele de Outro Teatro. Tivemos acesso a sua tese para obtenção do título de Professor Titular em Estudos da 
Performance, intitulada Outro Teatro: do ritual à performance (2015), na qual ele apresenta seus estudos para a concepção do que seria este Outro Teatro. Neste artigo, além de trechos da entrevista, contemplamos alguns excertos desta obra, na tentativa de complementar e aprofundar nossos conhecimentos sobre o Outro Teatro, visto que o consideramos uma teoria fundamental e necessária para a formação de professores(as) de teatro em história e cultura afro-brasileiras.

[...] quando falo de "Outro Teatro", não se trata de uma forma particular de teatro encontrado em determinado país e em determinado contexto. Refirome a uma prática indistinta quanto à sua localização geográfica e/ou histórica, mas que apresenta características peculiares como a inclusão intrínseca do ritual, do cantar-dançar-batucar, da participação ativa do público e o emprego de "motrizes culturais", termo por mim cunhado para definir as práticas culturais desenvolvidas em rituais que visam à restauração de comportamentos ancestrais a partir de tradições africanas e ameríndias (LIGIÉRO, 2015, p.102).

$\mathrm{Na}$ entrevista, o professor conta que no livro Corpo a Corpo: estudos das performances brasileiras (2011) ele partia do princípio de que as manifestações afroameríndias trazem a tríade dançar/cantar/batucar e, agora, na continuidade de suas pesquisas, ele incluiu o contar, passando a ser um quarteto: dançar/cantar/batucar/contar.

Para Ligiéro (2016, informação oral ${ }^{8}$ ), é fundamental que os(as) estudantes de teatro tenham conhecimento sobre estas tradições, entendendo-as "não como algo do passado, mas como algo que está presente no nosso caminhar, na nossa comida, na nossa fala, no nosso comportamento, na nossa maneira de amar, na nossa maneira de sentir". O professor ressalta que isto "não é considerado como parte do legado africano ou parte do legado ameríndio, mas parte de uma brasilidade genérica" (LIGIÉRO, 2016). Ele questiona de onde veio esta brasilidade:

Tem que haver uma discussão sobre as tradições. Deveria haver mais cursos sobre as estéticas afro e as estéticas ameríndias, porque estas estéticas são muito complexas, e são milenares. Se você estudar a tapeçaria dos povos andinos, ameríndios andinos, se você estudar a cerâmica, as diferentes cerâmicas maia, inca e asteca, são cerâmicas incríveis. Se você estudar as danças africanas, que são tão variadas, iorubá, as danças de Togo, as danças de Moçambique, as danças de Angola, centenas de danças. Então são estéticas que nos são muito familiares, porque estas estéticas aparecem no samba, no frevo, em várias representações gráficas, representações pictóricas. No entanto, isto não é falado, isto não é valorizado. (LIGIÉRO, 2016).

O docente relata que as escolas e universidades ainda não assimilaram as tradições africanas e ameríndias e que esta realidade precisa ser transformada. No entendimento do professor, existem duas discussões: 
Uma discussão que passa pela questão racial, dos preconceitos, pela questão da afirmação. E uma outra questão que é cultural. Porque as culturas africanas e ameríndias são culturas muito profundas e ambas ligadas à natureza. E são culturas em que se prioriza a arte, a música, a dança, a capoeira, as artes visuais, a poesia. Porque são culturas milenares e que trabalham com a harmonia do ser humano com a natureza, e isto tudo é banido do ensino tradicional. Pois o mesmo é voltado para a produtividade. Voltado para a competitividade, dentro da sociedade capitalista, para o treinamento, e não tanto para formação humanista. Então, eu acredito que existe ainda muito para se fazer. (LIGIÉRO, 2016).

Zeca Ligiéro diz contar com referenciais de alguns pensadores, dentre os quais Augusto Boal ${ }^{9}$ e Paulo Freire, ${ }^{10}$ que oferecem importantes subsídios teóricos. O professor tem trabalhado com o Teatro do Oprimido nos últimos dez anos e tem vários orientandos pesquisando sobre o tema. O professor conheceu Boal em vida, teve oportunidades de conversar com ele e também foi curador do seu acervo. Em sua obra inédita, ele resume bem seu pensamento sobre as propostas de Boal:

Com Boal, as preocupações iam além do artístico e das questões psicológicas e educacionais. Interessava-se pela expressão do ser como um todo, sua capacidade de desenvolver e articular ideias próprias, mas adicionava uma agenda mais política, buscando compreender os próprios sentimentos em relação às situações de opressão em que era vítima ou que, porventura, apresentava-se como o opressor. Portanto, desde os seus primeiros livros, sua finalidade inicial não era unicamente a expressão da arte em si mesma, mas sobretudo afinar a arte do participante (ator ou não ator) como instrumento de libertação rumo à transformação da sociedade na busca da cidadania plena. (LIGIÉRO, 2015, p. 391).

O docente nos relata que, em sua última fase, Boal trabalhou com a estética do oprimido, retomando certos princípios da década de 1960, afirmando que todos(as) nascemos artistas, e é o mundo que faz com que percamos a sensibilidade artística. Nesse sentido, no entendimento do professor, cabe às artes, ao teatro, a recuperação desta sensibilidade.

O Boal diz que a estética é uma forma de conhecimento. Uma forma de percepção da realidade, através dos sentidos. Nós perdemos isso, porque nos tornamos massacrados pela indústria cultural. Nós somos o que nós lemos, o que nós ouvimos e o que nós vemos. E o que nós vemos e consumimos é tudo o que a indústria cultural nos impõe através das mídias. Cabe ao teatro esta missão quase impossível, de criar estas ilhas e de criar uma rede de trocas, como a gente está trocando agora aqui, batendo nosso papo, e você vai escrever este texto e quem sabe outras pessoas vão se animar também a trabalhar esta ideia do Outro Teatro, que na realidade é o teatro de nós mesmos (LIGIÉRO, 2016).

O professor nos fala que, para ele, o aprendizado em teatro se dá pela prática e pelo contato com mestres(as). O aprendizado em teatro também é uma expressão oral, que se aprende por meio do contato com o fazer, com a investigação, e não com a reprodução de 
fórmulas. Para ele, o professor de teatro deve ser uma pessoa que está sempre criando, pois teatro "é sinônimo de criação" (LIGIÉRO, 2016). Ele revela uma preocupação com montagens teatrais feitas nas escolas a partir do texto escrito por autor(a) importante, sem conexão com a realidade e o interesse dos(as) alunos(as).

Eu acho que existe uma técnica aí, que é importante, interessante, mas é muito mais ligado à arte do ator, e não tanto do professor de teatro, que vai trabalhar em grande escala, para vários alunos de escola. O teatro que deve ser encorajado nas escolas é um teatro que o ator, o aluno, se sinta à vontade para fazer e que dê vontade nele de subir ao palco, e não o teatro que vai afugentá-lo porque ele tem que decorar o papel, ele tem que fazer uma coisa que não é dele. Então eu acho que quanto mais autonomia você der para o estudante, e ele se sentir parte da criação, eu acredito que isso é a grande chave do teatro na escola, porque vai ser uma coisa viva. Pode ser que o grupo que você esteja trabalhando descubra uma peça que eles querem montar. [...] o teatro deve ser descoberto pelo professor e pelo aluno, de um encontro. (LIGIÉRO, 2016).

No entendimento do docente entrevistado, o(a) professor(a) precisa conhecer com quem ele(a) está trabalhando, e o ensino de teatro é algo compartilhado. Para ele, quando é realmente incorporado à sala de aula, o teatro provoca mudanças significativas. $\mathrm{O}$ teatro é um grande operacionalizador de mudanças nos indivíduos, e seu objetivo na escola, segundo Ligiéro (2016), às vezes não é formar o ator, é um trabalho coletivo, para que as pessoas se sintam parte deste coletivo e "valorizadas como seres humanos e [para] que elas percebam que sua voz é ouvida". Há a percepção de que podem "ter liberdade de falar, liberdade de agir" (LIGIÉRO, 2016). Para o docente, o teatro desenvolve o potencial crítico, alimentando a vitalidade do pensamento.

Ligiéro (2016) considera que as tradições afro e ameríndias não são voltadas ao passado, elas são "um aproveitamento do que nós temos dentro de nós, uma consciência de que nós herdamos a tradição, e se nós nos alimentarmos destas tradições, nós teremos ainda muito a aprender, porque elas são milenares". O que ainda é ensinado nas escolas é que o teatro nasceu na Grécia, mas ele é muito anterior a isso e possui muitas formas diferentes. $\mathrm{O}$ docente relata ainda que há diferentes tipos de teatro entre os indígenas, os africanos, e outros teatros:

Como o teatro chinês e o teatro japonês, e o teatro da Índia, são muito anteriores ao teatro da Grécia, e nós não sabemos nada deles. Não é verdade que o único teatro é o da Grécia. Nós podemos, também, dialogar com estes outros teatros, que eles vão nos revelar formas de fazer teatro que são muito diferentes desta forma de pegar um texto, montar um texto, enfim. Exatamente, a palavra teatro, na língua muito antiga da Índia, sânscrito, chama-se natya. Natya quer dizer dança e teatro, a mesma palavra. Então, quer dizer, o corpo que conta história é o corpo que dança sem contar história, é natya. A gente pode trabalhar o teatro com a dança. Porque na 
África também, o griot conta, canta e dança, etc., enfim. Tudo isso são formas que o professor de teatro deve conhecer. (LIGIÉRO, 2016).

O docente propõe a inclusão do manancial criativo das estéticas afro e ameríndias nas escolas, que acabam não fazendo parte do nosso cotidiano porque são extremamente estereotipadas pela mídia. É preciso um desmonte desta historiografia eurocêntrica, que destitui a autoria da população negra. Há uma historiografia eurocêntrica das artes, do teatro, da música. É preciso que haja um reconhecimento das motrizes culturais afro-brasileiras: ${ }^{11}$

[...] procuro perceber uma associação de diversas matrizes culturais na construção de motrizes afro-brasileiras, capazes de se reconstruir na diáspora das Américas, reconfigurando elementos étnicos originários de diferentes países da África em rituais e festividades também oriundos daquele continente, mas reprocessados e recriados dentro do contexto opressivo colonial português ou espanhol, muitas vezes tutelado pela igreja e sob o guarda-chuva de um santo protetor, em que o ritual africano é restaurado dentro de uma nova moldura cristã, como foi o caso da congada ou da folia de reis. (LIGIÉRO, 2015, p. 416).

Nesse contexto, é preciso pensar em uma nova historiografia do teatro, reconhecendo suas diferentes formas. As tradições afro-ameríndias precisam ser revisitadas não só a partir da história mas também dos valores civilizatórios que nos trazem e nos constituem. Ligiéro analisa as aprendizagens dentro destas tradições, passando pelas questões da coletividade e da individualidade:

Eu acho que o que é interessante das tradições africanas e ameríndias é que o indivíduo aprende a ser do grupo, a ser coletivo, mas a ter seu próprio estilo de ser, a ter sua própria maneira de ser. Sua maneira de pensar. Esta questão do espaço, do indivíduo dentro do coletivo, é uma coisa muito do afro e do ameríndio. Porque você percebe uma dança em um coro feminino em uma escola de samba, você tem uma ala de baianas em que cada uma dança em um estilo, mas ela não erra o passo. [...] Ninguém imita ninguém. Elas têm uma relação com a dança, com o conhecimento ancestral, como forma de ser, com relação com o próprio corpo. Eu acho que é uma outra maneira de ser que a cultura não descobriu, não entrou em contato com a tradição oral. Acho que esta é uma nova chave: como a tradição oral pode entrar na escola, como a tradição oral pode entrar na universidade? (LIGIÉRO, 2016).

No entendimento do entrevistado, a transformação passa pelo convívio com a comunidade, buscando novas formas de entender a construção do conhecimento, trazendo para a escola novas formas de perceber e se relacionar com o mundo.

Só uma escola que convive com a comunidade pode ser transformada. Enquanto a escola se achar a dona do saber, ela vai estar reproduzindo a estética eurocêntrica, e a estética do opressor. Só a partir do momento em que a escola se abrir para as tradições orais, elas vão poder se reciclar, porque elas vão poder se beneficiar de conhecimentos milenares, que estão 
ao lado da sua porta. Mas que elas são cegas. Elas foram treinadas para enxergarem só o que está na frente, e não o que está em volta. Enquanto a escola não se abrir para a comunidade, porque a comunidade não está morta, a comunidade está viva. (LIGIÉRO, 2016).

Em diferentes momentos, o professor reforça a necessidade de trazer os(as) mestres(as) para dentro da escola, para dentro da universidade. Ele afirma que não é contra o ensino da história europeia, mas temos que compreender que não é a única, existem muitas outras formas de conhecimento. Outro ponto destacado por ele diz respeito à tradição:

[...] eu acredito que a tradição, para estar viva, ela está sendo modificada o tempo todo. Mas ela está preservando a sua essência, a sua vitalidade, os seus princípios. Eu acho que uma escola, para ela realmente ser transformadora, ela tem que trazer para dentro os mestres. [...] Temos que tratar as tradições afro-ameríndias em mesmo pé de igualdade que a cultura ibérica. (LIGIÉRO, 2016).

Nesse sentido, o professor considera que a transformação por meio do teatro acontece a partir das vivências, do contato com a realidade. O contexto, as pessoas envolvidas, as situações vivenciadas são parte fundamental para a criação teatral.

Por meio desta entrevista foi possível compreender as várias possibilidades de formação inicial de professores(as) de teatro em história e cultura afro-brasileira e africana pelo viés do Outro Teatro. Aliando formação prática, investigativa, que parte da própria história de cada um, mas que também leva em conta o coletivo, além do contato com mestre(as), trazendo a oralidade e novas formas de conhecimento para a universidade.

\section{Currículo e questão étnico-racial}

No entendimento de Silva (2011, p. 100), “a identidade étnica e racial é, desde o começo, uma questão de saber e poder". O autor aponta para o caráter cultural dos termos raça e etnia, que, por causa do "processo histórico e discursivo de construção da diferença", passam por "um constante processo de mudança e transformação" (SILVA, 2011, p. 100-101). Para o autor, "currículo é, sem dúvida, entre outras coisas, um texto racial" (SILVA, 2011, p. 102).

A questão da raça e da etnia não é simplesmente um "tema transversal": ela é uma questão central de conhecimento, poder e identidade. O conhecimento sobre raça e etnia incorporado no currículo não pode ser separado daquilo que as crianças e os jovens se tornarão como seres sociais. A questão tornase então: como descontruir o texto racial do currículo, como questionar as narrativas hegemônicas de identidade que constituem o currículo? (SILVA, 2011, p. 102). 
Nesse sentido, de acordo com Silva (2011), a construção de um currículo crítico demandaria pensar a diferença em sua dimensão histórica e política. O simples acréscimo de informações sobre outras culturas e identidades não torna o currículo multiculturalista. A grande questão não é apontar a diferença e a diversidade, mas questioná-las a partir das relações de poder e dos mecanismos que mantém esta categorização da humanidade em grupos dominantes e subordinados. Assim, o racismo deve ser entendido em sua forma ampla, não ligado à questão individual, mas à questão estruturadora da formação social. É fundamental, ainda, não se ater a abordagens étnicas e raciais essencialistas, que veem as identidades como fixas.

O conceito de representação assume centralidade, pois a partir dele pode-se pensar que não há verdade absoluta, na medida em que as construções das identidades dependem das relações de poder.

O oposto da representação racista de uma determinada identidade racial não é simplesmente uma identidade "verdadeira", mas uma outra representação, feita a partir de outra posição enunciativa na hierarquia das relações de poder. Um currículo crítico que se preocupasse com a questão do racismo poderia precisamente colocar no centro de suas estratégias pedagógicas a noção de representação tal como definida pelos Estudos Culturais. Essa noção permitiria deslocar a ênfase de uma preocupação realista com a verdade para uma preocupação política com as formas pelas quais a identidade é construída através da representação. (SILVA, 2011, p.104).

A proposição de currículo de Silva (2011) coaduna com a teoria fanoniana, de que só é possível entender a dinâmica da construção das diferenças por meio do estudo do colonialismo. A obra de Fanon situa-se na base de três movimentos contemporâneos: estudos culturais, estudos pós-coloniais e decoloniais, e cada corrente possui uma leitura diferenciada da questão. No livro Pele negra, máscaras brancas, Fanon (2008) apresenta uma reflexão sobre o impacto do colonialismo na subjetividade do colonizado. Segundo o autor, a concepção filosófica europeia se desviou do colonialismo. O colonialismo é fundamental para se compreender tanto as questões econômicas quanto as questões filosóficas da ciência, da ética e da estética.

Fanon (2008) propõe um novo humanismo, tendo como base o estudo de como as diferenças são criadas. Ele discute os impactos do colonialismo e busca uma desconstrução do que foi naturalizado como ser negro. Podemos considerar as questões que permeiam a obra de Fanon como atuais, na medida em que o colonialismo econômico é substituído pelo colonialismo cultural. 
Gomes (2012) propõe a descolonização do currículo a partir de mudanças de práticas e representação, do questionamento das relações de poder que incidem na sociedade e, portanto, também na educação. Essas mudanças pressupõem uma mudança para um novo paradigma, "que compreende que não há hierarquias entre conhecimentos, saberes e culturas, mas, sim, uma história de dominação, exploração, e colonização que deu origem a um processo de hierarquização de conhecimentos, culturas e povos" (GOMES, 2012, p. 102).

Este processo de rompimento com o paradigma hegemônico - do eixo ocidental, que aceitava um único tipo de conhecimento como válido - é fundamental, pois o processo histórico revela a violência e o terror cometidos por alguns grupos que tornaram sua cultura dominante, tida como paradigma civilizado, criando hierarquizações do conhecimento e considerando as outas culturas como inferiores. Gomes (2012, p. 102) propõe uma "ruptura epistemológica e cultural", por meio de novas formas de pensar a produção do conhecimento, reconhecendo a pluralidade de conhecimentos heterogêneos. Para a autora (2012), o silenciamento sobre a questão racial no currículo está ligado ao contexto do mito da democracia racial, que incide tanto na realidade social quanto na escolar. Este silenciamento poderá ser rompido a partir de uma "mudança cultural e política no campo curricular e epistemológico" (GOMES, 2012, p. 105). A partir da implementação da Lei 10.639/2003, não como conteúdo ou disciplina escolar, mas como "uma mudança estrutural conceitual, epistemológica e política" (GOMES, 2012, p. 106).

Portanto, a descolonização do currículo implica conflito, confronto, negociações e produz algo novo. Ela se insere em outros processos de descolonização maiores e mais profundos, ou seja, do poder e do saber. Estamos diante de confrontos entre distintas experiências históricas, econômicas e visões de mundo. Nesse processo, a superação da perspectiva eurocêntrica de conhecimento e do mundo torna-se um desafio para a escola, os educadores e as educadoras, o currículo e a formação docente. (GOMES, 2012, p.107).

As ações necessárias à mudança curricular para a implementação da temática envolvem um processo complexo. Se por um lado a criação de uma disciplina específica de educação para as relações étnico-raciais aparece como um elemento fundamental para que estudantes de todos os pertencimentos raciais tenham acesso ao vasto conhecimento da área, entendendo os processos históricos e o terror racial ${ }^{12}$ empreendido contra a população negra, por outro lado parece que há a necessidade urgente de que esta disciplina seja ministrada por uma pessoa que tenha ampla pesquisa nesta área. Dizemos isto porque muitos(as) profissionais não têm a percepção de que estão em uma estrutura social e racialmente construída, ainda consideram o Brasil uma democracia racial e não sabem lidar com as situações de racismo presentes no ambiente institucional, e, como vimos nas três trajetórias 
formativas dos entrevistados, trata-se de uma temática que esteve ausente na formação inicial dos três participantes.

Os(as) estudantes negros(as) estão cada vez em maior número nas universidades, e muitos não se sentem representados, além de serem muitos os relatos de vivências de situações de racismo institucional, conforme demonstrou a pesquisa de mestrado. Há também o fato de que estes(as) estudantes, sejam negros(as), brancos(as), indígenas ou de outros pertencimentos raciais, estão se formando e indo atuar na Educação Básica e, portanto, passando a ser responsáveis pela inserção da temática nas escolas.

O Pibid tem se mantido enquanto programa de formação por causa de pressão e resistência por parte de profissionais da educação. No entanto, entendemos o Pibid como importante meio de formação que tem obtido resultados positivos e deve ser fomentado, incentivado e ampliado. O Pibid também se constitui como importante espaço para que graduandos(as) possam planejar e experienciar práticas pedagógicas na perspectiva da educação para as relações étnico-raciais.

Pensar o currículo a partir de novas epistemologias nos abre campos de pesquisas ainda pouco explorados, que nos permitem estabelecer diferenciações e aproximações entre saberes. Nesse sentido, no campo do teatro, podemos pensar em propostas de formação a partir do Outro Teatro proposto por Zeca Ligiéro.

Devemos estender a questão do Outro Teatro a outros parâmetros para perceber que a teatralidade não reside apenas na psicologia dos personagens e na trama de seus destinos enquanto texto falado, mas, sobretudo, nos seus aspectos ritualísticos, fantásticos, metafísicos, expressos especialmente na combinação dos distintos elementos como a música, a dança, o uso de máscaras, o canto, a cenografia e a narrativa épica [...]. (LIGIÉRO, 2015, p.273).

No nosso entendimento, o Outro Teatro proposto por Ligiéro (2015) constitui importante proposição para se repensar a formação inicial de professores(as) de teatro na perspectiva da história e cultura afro-brasileira e africana. Isso porque traz aportes teóricos e metodológicos para se pensar uma reconceituação do fazer teatral. A mudança curricular na perspectiva da Lei 10.639/2003 é praticamente impossível de ser encontrada enquanto não se pensar a partir do Outro Teatro.

A temática étnico-racial e a cultura afro-brasileira se efetivarão na formação inicial de professores(as) de teatro com o rompimento da barreira entre universidade e comunidade. Nesse sentido, podemos (re)pensar a formação inicial de professores(as) de teatro na perspectiva do Outro Teatro: reconhecimento das tradições milenares como portadoras e produtoras de saberes; compreensão das performances culturais a partir dos contextos sociais, 
étnicos, raciais e históricos. $\mathrm{Na}$ perspectiva das novas epistemologias, é preciso o reconhecimento dos diferentes tipos de conhecimentos, trazendo os(as) mestres(as) para dentro da universidade. Ainda se torna indispensável a formação em educação para as relações étnico-raciais, para o entendimento do processo histórico marcado pela racialização, por racismo e discriminações, ainda presentes na sociedade, que só serão combatidos efetivamente no campo das práticas.

As performances afro-brasileiras como pedagogias culturais ${ }^{13}$ são imprescindíveis à formação inicial de professores(as) de teatro. Estas manifestações constituem-se em estéticas próprias, marcadas por elementos como a dança, o canto, a música, a oralidade, a tradição e o ritual. Os(as) estudantes precisam conhecer diferentes formas de fazer e pensar o teatro, para que possam atuar na Educação Básica valorizando as diferenças e reconhecendo a multiplicidade de manifestações culturais.

Num momento em que certas razões epistemológicas proporcionam
mudanças radicais no estatuto ontológico da arte, influenciando os
fundamentos e as práticas escolares, fica evidente que está em processo uma
ressignificação do ensino de artes, no qual passa a ser requerido, na
perspectiva do currículo, um trabalho pedagógico que explore as questões
que se insinuam no cotidiano, porém inserindo-as na dimensão do simbólico
para que possam ser repensadas como se tivessem natureza extracotidiana,
sem valor imediato, essencial para o bem-estar do ser. Dessa maneira, o
interesse pela performance, como linguagem de interações e expressividades,
passa a ocupar o imaginário humano com alguns temas deveras pungentes, a
saber: rompimento com as definições rígidas de arte, artista, espectador, obra,
texto, imagem, ritmo ou cena; surgimento de maneiras especulativas de
percepção e fruição; aparecimento de formatações inusitadas e geralmente
multidirecionadas; emergência da arte enquanto matéria da própria vida. Em
face desses questionamentos, a discussão requer uma abordagem
interdisciplinar do problema e, nesse particular, a temática da performance
assume-se enquanto vertente natural de uma pedagogia assentada na cultura,
instaurando-se como maneira possível de alinhavar muitas das inquietações
ainda não resolvidas no âmbito da escolarização. (SANTANA, 2014, p. 59).

Assim, propomos formação cultural e também política, para que a atuação dos(as) futuros(as) professores(as) considerem e partam dos saberes ancestrais da cultura afrobrasileira em suas práticas pedagógicas, mas que também tenham a sensibilidade para identificar as situações de violências raciais, sendo capazes de propor ações de combate ao racismo.

A formação inicial de professores(as) de teatro deve almejar a formação de um(a) profissional capaz de promover uma nova postura com relação ao ensino de arte e de teatro na escola. Para tanto, a formação inicial deve proporcionar o trabalho com as diferenças e com a diversidade de manifestações culturais e de concepções sobre o teatro e a própria arte, em contexto mais plural. 


\section{Notas}

${ }^{1}$ A Lei 10.639/2003 alterou a Lei 9.394/1996 estabelecendo a obrigatoriedade do ensino de história e cultura afro-brasileira e africana na Educação Básica. Em 2008, foi alterada pela Lei 11.645, para incluir no currículo oficial da rede de ensino a obrigatoriedade da temática "História e Cultura Afro-Brasileira e Indígena". Neste artigo, optamos por fazer referência à Lei 10.639/2003 como marco para implementação da temática na Educação Básica. No que diz respeito ao campo normativo, nas Diretrizes Curriculares para o Ensino de História e Cultura Afro-brasileira e Africana e para Educação das Relações Étnico-raciais, a Arte é considerada área prioritária para o trabalho com a temática na Educação Básica.

${ }^{2} \mathrm{O}$ trabalho foi aprovado pelo Comitê de Ética em Pesquisa da Universidade Federal de São Carlos, Parecer ${ }^{\circ}$ 1.402.119, em 3 de fevereiro de 2016.

${ }^{3}$ Com relação aos docentes e à docente entrevistados(a), após um acordo e a autorização de parte deles(a), ficou combinado que seriam utilizados seus nomes verdadeiros..

${ }^{4}$ Entrevista concedida à Monique Priscila de Abreu Reis. São Paulo: UFSCar, 2016. Áudio Mp3. As demais menções ao prof. Ricardo Figueiredo com esta mesma data dizem respeito a entrevista em questão .

${ }^{5}$ Ligiéro, Zeca. Teatro e comunidade, uma experiência. 1. ed. Uberlândia: Editora da Universidade Federal de Uberlândia, 1983.

${ }^{6}$ Entrevista concedida à Monique Priscila de Abreu Reis. São Paulo: UFSCar, 2016. Áudio Mp3. As demais menções à prof. Carminda Mendes com esta mesma data dizem respeito a entrevista em questão.

${ }^{7}$ No texto Para além do pensamento abissal, de Boaventura Sousa Santos (2007), o termo abissal está relacionado à ideia de abismo, que é intransponível. Assim, o pensamento abissal seria o não racional, o que está fora da conceitualização da civilização. $\mathrm{O}$ autor divide a produção do conhecimento pelo que chama de linhas abissais, que seriam duas: este lado da linha e o outro lado da linha, sendo o primeiro ligado ao colonizador (norte) e o segundo ligado ao colonizado (sul). No pensamento abissal, a copresença dos dois lados da linha é impossível. As linhas abissais separam deste lado da linha a ciência, a filosofia e a teologia, ficando do outro lado da linha os conhecimentos considerados "incomensuráveis e incompreensíveis por não obedecerem nem aos critérios científicos de verdade nem aos critérios dos conhecimentos reconhecidos como alternativos, da filosofia e da teologia" (SANTOS, 2007, p. 74). Para Santos (2007), o pensamento pós-abissal é um pensamento de resistência ao abismo. No pensamento pós-abissal a ciência perde a confiança epistemológica e se vê forçada a partilhar o campo do saber com conhecimentos rivais, ou seja, não científicos. Estes conhecimentos não científicos passam a gerar formas diferentes de poder (SANTOS, 2007, p. 78).

${ }^{8}$ Entrevista concedida à Monique Priscila de Abreu Reis. São Paulo: UFSCar, 2016. Áudio Mp3. As demais menções ao prof. Zeca Ligiéro com esta mesma data dizem respeito a entrevista em questão.

${ }^{9}$ Augusto Boal (1931-2009) foi diretor teatral, autor e teórico. Desenvolveu a teoria do Teatro do Oprimido, tornando-se referência tanto no teatro brasileiro quanto no teatro mundial. Foi nomeado como embaixador mundial do teatro pela Unesco em 2009.

${ }^{10}$ Paulo Freire (1921-1997) foi um educador brasileiro, autor de vários livros, dentre os quais Pedagogia do Oprimido. É reconhecido mundialmente pelo pensamento pedagógico centrado na conscientização e emancipação dos(as) estudantes.

${ }^{11}$ Conceito utilizado por Ligiéro (2011, p. 107) para "definir um conjunto de dinâmicas culturais utilizadas na diáspora africana para recuperar comportamentos ancestrais africanos. A este conjunto chamamos de práticas performativas, e se refere à combinação de elementos como a dança, o canto, a música, o figurino, o espaço, entre outros, agrupados em celebrações religiosas em distintas manifestações do mundo afro-brasileiro".

${ }^{12}$ Gilroy (2001, p. 158), no livro $O$ Atlântico Negro, utiliza a expressão terror racial para se referir aos "terrores indizíveis da experiência escrava" e em contraposição à ideia de racionalidade como característica da modernidade, já que a escravidão e os processos de racialização aconteceram neste período. Para o autor "a proximidade dos terrores inefáveis da escravidão foi mantida viva - cuidadosamente cultivada - em formas ritualizadas, sociais" (GILROY, 2001, p. 158). Neste artigo, utilizamos a expressão terror racial em referência às violências raciais cometidas contra a população negra: preconceitos, racismo, discriminações, violação de direitos, descaso com relação a políticas públicas para a saúde da população negra, violência obstétrica sofrida por mulheres negras, encarceramento em massa de pessoas negras. Cf.: Brasil (2015).

${ }^{13}$ No entendimento de Hernández $(2014$, p. 333), o conceito de pedagogias culturais propõe uma "visão ampliada do pedagógico, no sentido apontado por autores da pedagogia crítica como Freire, Luke, Giroux, Kincheloe e McLaren". Considerando "o terreno pedagógico como prática de produção de identidade ou práxis através da qual aprendemos a ver a nós mesmos em relação ao mundo" e considerando que a educação acontece em diferentes contextos, não se limitando apenas à escolarização, faz-se um deslocamento do "pedagógico do saber disciplinar relacionado com as Ciências da Educação para vinculá-lo à cultura e à ação política (HERNÁNDEZ, 2014, p. 333)". A aproximação das pedagogias culturais tem o condão de "descentrar o pedagógico do escolar - do educativo - e levá-lo à cultura e outras práticas sociais mediadoras de posições de identidade" (HERNÁNDEZ, 2014, p. 334). 


\section{Referências}

ANDRÉ, Carminda Mendes. Carminda Mendes André: entrevista. [agosto, 2016]. Entrevistadora: Monique Priscila de Abreu Reis. São Paulo: UFSCar, 2016. Áudio Mp3.

BRASIL. Conselho Nacional de Educação. Conselho Pleno. Parecer no 3, 10 de março de 2004. Diretrizes Curriculares Nacionais para a Educação das Relações Étnico/Raciais e para o Ensino de História e Cultura Afro-Brasileira e Africana. Diário Oficial da União: Brasília, DF, Seção 1, p. 11, 22 jun. 2004. Disponível em: https://bit.ly/2psGyRO. Acesso em: 20 nov. 2018.

BRASIL. Presidência da República. Secretaria-Geral da Presidência da República. Secretaria da Juventude. Mapa do encarceramento: os jovens do Brasil. Brasília: Editora da Presidência da República, 2015. (Série Juventude Viva). ISBN 978-85-85142-62-9.

FANON, Frantz. Pele negra, máscaras brancas. Tradução de Renato da Silveira. Salvador: EDUFBA, 2008.

FIGUEIREDO, Ricardo Carvalho de. Ricardo Carvalho de Figueiredo: entrevista. [junho, 2016]. Entrevistadora: Monique Priscila de Abreu Reis. São Paulo: UFSCar, 2016. Áudio Mp3.

GOMES, Nilma Lino. Relações étnico-raciais, educação e descolonização dos currículos. Currículo sem Fronteiras, [S. l.], v. 12, n. 1, p. 98-109, jan./abr. 2012.

HERNÁNDEZ, Fernando. Pedagogias Culturais: o processo de (se) constituir em campo que vincula conhecimento, indagação e ativismo. In: MARTINS, Raimundo; TOURINHO, Irene (org.). Pedagogias Culturais. Santa Maria: Editora da UFMS, 2014

LIGIÉRO, Zeca. Corpo a corpo: estudo das performances brasileiras. Rio de Janeiro: Garamond, 2011.

LIGIÉRO, Zeca. Outro Teatro: do ritual à performance. 2015. Tese (Professor Titular) - Escola de Teatro, Universidade Federal do Estado do Rio de Janeiro, Rio de Janeiro, 2015.

LIGIÉRO, Zeca. Zeca Ligiéro: Entrevista. [agosto, 2016]. Entrevistadora: Monique Priscila de Abreu Reis. São Paulo: UFSCar, 2016. Áudio Mp3.

REIS, Monique Priscila de Abreu. A formação de professores/as de Arte em educação para as relações étnico-raciais: interrogando os currículos de Licenciatura em Teatro. 2017. 159f. Dissertação (Mestrado). Universidade Federal de São Carlos, SP.

SANTANA, Arão Paranaguá de. Trajetórias, avanços e desafios do teatro-educação no Brasil. Sala Preta, São Paulo, v. 2, p. 247-252, 2002. https://doi.org/10.11606/issn.2238-3867.v2i0p247-252.

SANTANA, Arão Paranaguá de. Teatro e formação de professores. São Luís/MA: Editora da UFMA, 2010a.

SANTANA, Arão Paranaguá de. A Experiência Estética com Fundamento da Preparação Docente: um Estudo de Caso. In: CONGRESSO DA ABRACE: ASSOCIAÇÃO BRASILEIRA DE PESQUISA E PÓS-GRADUAÇÃO EM ARTES CÊNICAS, 6. São Paulo, 2010b. Anais [...]. , 2010b. p. 1-5. Disponível em: https://bit.ly/30eoGt7. Acesso em: 11 set. 2016

SANTANA, Arão Paranaguá de. Experiência e Conhecimento em Teatro. São Luís: EDUFMA, 2013. 
SANTANA, Arão Paranaguá de. Corpo, arte, vida e educação: contribuições da performance para as pedagogias culturais. In: MARTINS, Raimundo; TOURINHO, Irene (org). Pedagogias Culturais. Santa Maria: Editora da UFMS, 2014.

SANTOS, Boaventura Sousa. Para Além do Pensamento Abissal. Das linhas globais a uma ecologia dos saberes. Novos Estud., São Paulo, n. 79, p. 71-94, nov. 2007. http://dx.doi.org/10.1590/S010133002007000300004 .

SILVA, Tomaz Tadeu da. Documentos de identidade: uma introdução às teorias do currículo. Belo Horizonte: Autêntica, 2011.

STRAUSS, Anselm; CORBIN, Juliet. Pesquisa qualitativa: técnicas e procedimentos para o desenvolvimento de teoria fundamentada. 2. ed. Porto Alegre: Artmed, 2008.

WAISELFISZ, Julio Jacobo. Mapa da Violência 2016. Homicídios por arma de fogo no Brasil. [S. l.]: Flacso Brasil, 2016. Disponível em: https://bit.ly/2bVB1fk. Acesso: 23/02/2017. 